\title{
VIII. Experiments and observations tending to show the composition and properties of urinary concretions
}

\section{George Pearson M.D. F.R.S.}

To cite this article: George Pearson M.D. F.R.S. (1798) VIII. Experiments and observations tending to show the composition and properties of urinary concretions, Philosophical Magazine Series 1, 2:5, 38-54, DOI: 10.1080/14786449808676876

To link to this article: http://dx.doi.org/10.1080/14786449808676876

曲 Published online: 18 May 2009.

Submit your article to this journal $\pi$

Џll Article views: 2

Q View related articles $\longleftarrow$ 
VIII. Experiments and Obfervations tending to flow the Compofition and Properties of Urinary Concretions. By George Pearson, M.D. F.R.S. Read before the Roval Society, December 14, 1797. From the Philofophical Tranfactions.

\section{Hiforical Obfervations.}

$\mathrm{T}$

H E notion generally entertained, of the nature o? u inary concretions, conffted with the names given them *, till the lat twenty years; although the experiments of Slare, Frederic Hoffman, and Hales, long before howed that thefe fubftances commonly confitt of animal matter. Galen indeed

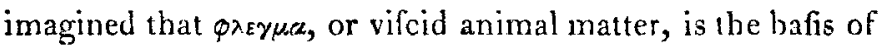
animal concretions; but, in his days, earth was believed to be the bafis of animal matter. Alkaline medicines were, however, employed by the Greek phyficians in difeafes from calculi.

The experiments of the alchemifts alfo made it appear that earth was only a part of the matter of concretions. It was probably the obfervation of the depofition and cryftallization of faline bodies, which fuggefled the notion of urinary calcult being of the nature of tartar. Such was the opinion of Bafil Valentine, and after him of Hochemer, better known by the name of Paracelfus; but, whether the latter adopted the denomination Duelecb from its import, or from caprice, has not been explained. Van Helmont, a century after his protolype Paracelfus, being fruck with the experiment in which he difcovered the concretion of falts in

* Urinary concietions have obtained their denominations, like most other things, from their obvious properties. Accordingly, in our language, they are popnlatly known by the nanes stone and gravel, or sard, from their reserblance to the states of eath so nanted and we find names of the same import in other languages, such as $\lambda_{6} \theta_{2}$, (A R E T EUs);

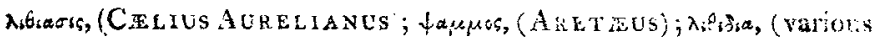
authors); calculas, (CELsUS and $\mathrm{FLINY}$ ); salinim, (varions authors) In other languages, and especially in those now s c cken, it is urnecesna: $y$ to notice names which have the same meaning. 
diftilled urine by alcohol, was led to depart from his adored mafter's opinion, with refpect to the nature of calculi; although he acknowledges the merit of Paracelfus, in having difcover d the folvent Ludus, (a calcareous ftone alfo called Septarium,) which Van Helmont fays is preferable to alkaline lixivium. He alfo fays, that $\mathrm{w}$ hen the archeus fpirit of urine meets with a volatile earthy firit, and does not act in a due manner, a concretion will be formed; but, in a healthv fate, although all urine contains the matter of urinary calculi, no cuncretion can take place, becaufe the archeus, or vital power of the bladler, counteracts its formation.

As to the kind of earth compofing calculi, the only diftinction of earths, till about the laft balf century, was into abforbent and non-abforbent; but, fince the abforbent earths were diftinguifhed into calcareous, magnefia, and alumine or clay, the calcareous was confidered to be the earth of urinary concretions; apparently however for no other reafon but its obvious properties, and its extenfive diffufion through the whole animal kingdom.

At length, viz. in 1776 , the experiments of the wonderful Scheele were publithed in Sweden, but were fcarcely known in this country till 1785 . Thefe experiments exploded the opinion of the earthy nature of calculi, and fubfituted that of their confifing of a peculiar acid, refembling the fuccinic, and of a gelatinous matter, without any earth. Afterwards about of their weight of lime was found by Bergman; which, for a caufe now well known, had eluded the acutenefs of Scheele. Although the experiments of Scheele were confeffedly unqueitionable, and were ably fupported by the learned Bergman, fome very eminent chenilts, having obtained different refults by their own experiments, adopted a different opinion of the compofition of thefe concretions. The immortal, and ever to be deplored, Lavoifier fuppofed thefe fubftances to confift of acidulous phofphate of lime and animal matter, many of them being partially 
fufible; but ftill it was the unrivalled Scheele who difcovered that the urine of healthy perfons contains fuperphofphate, or acidulous phofphate, of line; and who alfo indicated the experiment which verified his opinion, that phofphate of lime is the bafis of bone.

Experiments have been likewife made, for the moft part in a rather defultory way, and molt of them by perfons but little practifed in chemical inquiries, which at leaft afford evidence, that urinary concretions are very different, with refpect to the proportion of the ingredients in their compofition, and perhaps alfo in kind. M. Fourcroy, who however muft not be claffed with inexperienced chemifts, I believe firft obtained pruffic acid by fire, and by nitric acid, from thefe concretions; and howed that they fometimes contain phofphate of ammoniac and of foda; which may be diffolved out of them by water. M. Fourcroy alfo fays, he found magnefia in the inteitinal calculus of a horfe; which calculus was a triple combination, of one part of phofphate of ammoniac, two parts of magnefia, and one of water, befides traces of animal and vegetable matter.

Dr. Link, in a very elaborate differtation, publifhed at Gottingen, in 1788 , on urine and calculi, concludes that urinary concretions confift of phofphoric acid, lime, ammoniac, oil, the bales of different kinds of gazes, together with the acid fublimate of Scheele, although he did not fucceed in obtaining it.

It is a proof of Dr. Black's fagacity, that he fhould have been able to perceive, from a few experiments, that urinary concretions confifted of animal matter and the earth of bone, before the compofition of this earth was demonntrated by Gahn.

In this hiftorical ketch it mould be noticed, that alkaline fubftances, though uled by the Greek phyficians, and afterwards by the alchemical phyficians, appear to have been laid afide by the regular practioners, for a century or two preceding their revival, by the famous Mrs. Stephens, in 1720 . 
Her prefcription brought into vogue the theory of thefe medicines operating by their cauficity. The faccefsful ufe, by Mr. Colburne, of posalh faturated with carbonic acid, according to the difcovery of Bewley and Bergman, and the Atill further improvement in practice, from the ufe of foda, as well as potah, fuper-faturated with carbonic acid, by the difcovery of a peculiar method by $\mathrm{Mr}$. Schweppe, have completely refuted the theory of the agency of alkalies on the principle of caufticity.

It appears, from the preceding brief hittary, as well as from the confeftion of the lateft and beft writers, that the experiments hitherto made, rather " afford indications of what remains to bedone, than furnith demonftations of the nature of animal concretions." It is alfo too obvious to need explanation, that more efficacious and innocent practice, in difeafes from thefe concretions, can only be difcovered by a further inveftigation of their properties. It is with this view, as well as for the fake of chemical philofophy, that I think it 'my duty to fubmit to the Society fome of the obfervations I have made, in the courfe of inquiry on this fubject.

The obfervations which I thall now offer, are principally on a fubfance, which my experiments inform me is very generally a conftituent of both urinary and arthritic concretions. It is a fubitance obtained by diffolving it out of thefe concretions, by lye of caultic fixed alkali, and precipitating it from the folution by acids. In this way, Scheele feparated this matter; but he did not confider its importance, nor of courfe at all inveftigate its properties. He does not even feem to have been aware that it was a diftinet conftituent part of the urinary concretion; for, when be relates the experiment of precipitating malter from the nitric folution of calculus by metallic falts, no diftinction is made between the precipitations in this experiment, and that in the former : yet we can now thow, that in the one cafe the precipitate is a peculiar animal oxide, and in the other they are metallic 
phofphates. As Scheele obtained an acid fublimate, it has been imagined by fome writers, that the precipitate by any acid (even by the carbonic) from the alkaline menftrum, was an acid; the fame as that obtained by fublimation, and which, in the new fytem of chemiftry, has been denominated litbic acid. The following experiments thow that thefe fubftances are different fpecies of matter.

\section{Experiments.}

2.50 grains of a white, finooth, laminated, urinary calculus, and the fame quantity of a nut-brown one, with an uneven furface, both of which were of a roundith figure, were pulverized together* 300 grains of thefe pulverized calculi were triturated with three ounces and a half, by meafure, or five ounces, by weight, of lye of caufic foda. The mixture became thick, and copiouny enined ammoniacal gaz. After digeftion for a night, and then boiling, with the addition of five ounces of pure water, 1 obtaicied, by filtration, five ounces of clear colourlel's liquid. Boiling water was repeatedly poured upon the itrainer, till what paffed through it was almoft taftelefs, and remained clear, on the addition of diluted fulphuric acid.

(a) The matter remaining on the flainer, being dried, was an impalpable, white, taftelers, heavy powder, which weighed 96 grains:

(b) The five ounces of filtrated liquid, having been fet apart, on ftanding, depefited a white, opaque, granulated, foap-like matter, from a colourlefs clear liquid The liquid being decanted, the depofit was dried, and was then an opaque, brittle, foap-like matter, which diffolved readily in water, giving a clear but not vilcid folution, and

* The object of these experiments being principally to investigate the properties of on: of the constituent parts of urinary concretions, which part was previously determined (by the test of nitric acid), to exist in both these, it can be no objection to the experiments, that $I$ made use of a mix ture of two calculi. 
tafting weakly of foda. This foap-like matter weighed 28 o grains.

(c) The decanted liquor, $(b$,$) being mixed with the above$ filtrated liquors, on evaporation to three ounces, afforded no depofit on ftanding, although it was a very heavy and foapy liquid to the feel; but, on adding diluted fulphuric acid gradually, till it ceafed to become turbid, a fediment was depofited, which was a very light, white, impalpable powder, in weight, when dried, 26 grains. The liquid from which this powder was precipitated, being evaporated, afforded nothing but fulphate of forla, and a few grains of cryftals, which feemed to be phofphate of foda. There was alfo a blackifh matter, which burnt like horn, or other aninal matter, and did not leave a pink or rofe-coloured matter, on evaporating the folution of it in nitric acid to drynefs, but left a carbonaceous refidue; whereas, the white precipitate, fo treated, afforied a beautiful pink matter.

(d) $25^{\circ}$ grains of the foap-like matter (b) being diffolved in eight nunces of pure water;

I. A little of this folution, further diluted by one ounce of water, grew milky on adding a few drops of nitric acid, but became lefs fo on ftanding. On adding more nitric acid, and beating it, the mixture became quite clear: by adding a few drops of lye of cautic foda, a very flight curdy appearance took place.

2. On adding, to the fame diluted folution, a little of the diluted fulphuric or muriatic acid, millinefs enfued, and remained, although the acids were added till the mixture was extremely four. On adding lye of cauftic fola, much more than to faturate the fuperabundant auid, the mixture became clear again; and, on adding the acids a fecond time, the milkinefs was reproduced. It was found that the milkinefs could be produced and deftroyed, or clearnefs be produced, by the alternate addition of the acid and alkali, for an unlimited number of times. If the nitric acid however was ufed, at length no milkinefs could be induced. If carbonate 
of foda was added, in place of the canftic foda, the mixture could not be made elear.

3. Lime water was rendered turbid by this folution, but I neglected to examine the precipitated matter.

4. A little of the folution, with the addition of a few drops of concentrated nitric acid, being evaporated to drynefs, fometimes a pink, and at other times a blood-red, or rofe-coloured matter was left; which, by further application of fire, became black.

5. Carbonic acid, digefted and thook with this folution, did not render it turbid.

6. To the whole of the remaining folution was added diluted fulphuric acid, to faturate the alkali. On ftanding, a copious precipitate took place, from a clear liquid; which precipitate, being wathed and dried, was a mafs of very light, mica-like, whitih cryltals, amounting to 123 grains. It was eftimated that the folstion ufed in the Experiments $x .-5$. would have produced $\mathrm{I} 2$ grains, and that the 30 grains of foap-like matter, $(b$,$) not decompounded,$ would have yielded about 14 grains more.

(e) The precipitate, $(d, 6$.

I. Had no tafte, nor fruell, and did not diffolve in the mouth.

2. About one part of it only diffolved in 800 parts of boiling water; which folution did not redden paper ftained with turnfole, nor the folution and tincture of this teft; neither did it change turnfole paper, reddened by acid, to a blue colour. On cooling, the greateft part of what had been diffolved was depofited, in a cryftallized ftate, equally on the fides and bottom of the veffel. This cryftallized matter had the properties abovementioned $(d)$. Boiling water was found to diffolve a much greater proportion of urinary fione, and alfo of gravel, than of this precipitate.

3. Lye of mild potafh, or fubcarbonate of potah, being dropped into the folution $(e, 2$.) with its cryftallized depofit, the cryftals at firft feemed to diffolve; but, on ftanding, a 
great part of the matter was depofited, and the liquid remained turbid.

4. The precipitate being boiled with lye of carbonate of loda, more feemed to be diffolved than in pure water; but the folution was clear, and, on evaporating it nearly to drynefs, and pouring cold water upon it, on a paper ftrainer, fcarcely any thing but the foda paffed through with the water; the precipitate remaining behind on the paper. The refult was the fame, when this experiment was made with a lye of corbonate of ammoniac. The refult was alfo the fame, with water in which red oxyde of mercury had been boiled; which was alfo boiled with this precipitate, and filtrated after cooling.

5. A little of the precipitate being triturated with quicklime, hot water was poured upon it. The filtrated liquor gave the precipitate back again, on adding muriatic acid.

6. The precipitate expofed to flame, with the blow-pipe, turned black, emitted the fmell of burning animal matter, and evaporated or burnt away without any figns of fufion; ftaining the platina fpoon black.

7. Five grains of the precipitate, in balf an ounce of water, were left to ftand in a warm room, during the months of Auguft and September ldet, without any fign of putrefaction appearing, or any obvious change taking place.

8. Twenty-four ounces of boiling water were faturated with the precipitate, and divided in to fix portions; from each of which, on cooling, moft of it again precipitated.

The firft portion, on boiling with a little lye of carbonate of foda, (the pneumatic apparatus being affixed,) difcharged no carbonic acid into lime water; but a tranfparent folution was produced, and, on cooling, very little was precipitated.

The fecond portion was, in the fame manner, boiled in a little lye of cauftic foda; which gave a $\operatorname{tran} f_{\text {parent folution }}$ on cooling, without any precipitation. 
The third portion being boiled with lime water, very little more feemed to be diffolved than in pure water.

The fourth portion being boiled with 4 grains of fubphofphate of lime, or calcined bone, no more feemed to be diffolved on account of this addition.

Nor was more diffolved in the fifth portion, by the addition of 4 grains of phofphate of lime, made by dropping phofphoric acid into lime water.

And the refult was the fame with the fixth portion, to which were added 4 grains of fuperphofphate of lime, made by adding phofphoric acid to lime water, fo as juft to make a clear folution, and then evaporating the folution.

9. Urine feemed to diffolve, or at leaft to fufpend, a greater quantity of the precipitate than mere water; fo likewife did water with a little fulphate of foda.

10. The precipitate did not render folution of hard foap at all curdy; but on adding the precipitate to folution of fulphuret of potah, it became very turbid.

11. The precipitate produced a ftrong effervefcence, even in the cold, with nitric acid, but the fumes were not thofe of nitrous acid : there was a clear folution, which, on evaporation to drynefs, afforded black matter, furrounded by a pink, or blood-red margin.

12. The fubftance, with fulphuric acid, turned black, and emitted fumes copionfy, which were fearcely thofe of fulphureous acid; and, on evaporation, a black mark only was left.

13. I firt digefted, and then boiled, in water, the precipitate with pruffiate of iron; but the filtrated liquor afforded no precipitation with fulphate of iron.

14. Two drachms, by meafure, of nitric acid, of the fpecific gravity of 1,35 , were poured upon 7 grains of the precipitate. A violent effervefcence took place, which was foon fucceeded by a complete folution.

A few drops of this folution, being evaporated on glafs, 
left a black mark, furrounded by a pink margin. A few drops of nitric acid being evaporated from this refidue, nothing but a fill lefs black mark, and a few red fpots remaincd.

Nitric acid being added a third time, nothing but a black mark, fill fmaller, remained; which entirely difappeared, on evaporating this acid from it a fourth time.

I found that a few drops of this folution, fo diluted that they did not contain the $\frac{1}{7}$, or even a much fmaller part, of a grain of the precipitate, on evaporation, left a pink Aain on glafs.

The whole of the reft of the folution was difilled in a very low temperature, fo that a drop only fell about every half-minute, till a thick brownin fediment remained, with a red margin. A fimilar diftillation was performed, with the diflilled liquor, a fecond time, when there remained a little whition thick matter. On a third diftillation, as before, with the difilled liquor, towards the clofe white fumes arofe; and about half a drachm of liquil, which now remained in the retort, being left to fiand, prifmatical cryftals, decuffating each other, were formed. They had a harp tafte, but were fcarcely four; were very foluble in the mouth, and evaporated in white fumes, leaving a very Might black ftain.

15. Twenty grains of the precipitate were introduced into a tube, $\frac{3}{8}$ of an inch wide in the bore, fealed by melting at one extremity; which extremity was coated, and the tube was fitly bent for retaining fublimate, and collecting gaz. The temperature, from the fre applied, was at firt very low, but was gradually increafed, fo as to make the coated part, containing the charge, red hot. At firlt, the precipitate turned black, and a little water appeared. Secondly, gaz came over, which had the fmell of empyreumatic liquor cornu cervi. Thiruly, a brown fublimate appeared, and gaz as before, but alfo with pruffic acid gaz. Fourthly, black 
matter, faining the tube, as if from tar, or animal oil. On cooling, there was found a refidue, of nearly three grains, of pure carbon. The fublimate was principally carbonate of ammoniac; the reft was animal oil. The gaz difcharged was nearly half its bulk, or 5 cubic inches by meafure, carbonic acid; and the remaining 5 cubic inches were nitrogen gaz, containing pruffic acid and empyreumatic oil.

I treated in the fame manner, the fame quantity of reddith cryftals, depofited fpontaneoufly from urine. The refilt was not very different from that of the former experiment. The gaz was more offenfive, fmelling like putrid urine, and the carbonaceous refidue was more copious, and contained lime and phofphoric acid; at leat the lixivium of it became white, on dropping into it oxalic acid; and it became flightly curdy, on adding lime water.

I treated in the fame manner, fome quite round and finooth concretions, of the fize of black pepper feeds. The products were the fame as the former, but the gaz was ftill more offenfive, and in fmaller quantity; and the carbonaceous matter was more copious.

I, in the fame way, fubjected to experiment 20 grains of a nut-brown light calculus, which I had previouny afcertained to contain the matter above defcribed, which was precipitated from cautic foda by acids. The products were of the fame kind as the former; but I could find no trace of phofphoric acid in the refidue, which I did of lime, and the gaz was lefs offenfive. The carbonaceous refidue was not, in weight, 3 grains.

It will be proper, before I proceed further, to point out fome of the more obvious conclufions from the above experiments.

I. It appears that at leaft one half of the matter of the urinary concretions fubjected to the above experiments united to cauftic foda, and was precipitated from it by acids. (II. $a-d$.)

2. This 
2. This precipitate does not indicate acidity to the moft delicate tefts; $(e, 2$.$) and, as it is inodorous, taftelefs, (e, 1$. fcarcely foluble in cold water, $(e, 2$.$) does not unite to the$ alkali of carbonate of potah, of foda, or of ammoniac, $(e, 3,4$.$) nor to oxyde of mercury, (e, 4$.$) nor to the lime$ of lime-water, $(e, 8$.$) nor decompound foap, (e, 10$.$) or$ pruffiate of iron, (e, 13.) and, as its combination with cauftic foda refembles foap, more than any double falt known to confift of an acid and alkali, this precipitate does not belong to the genus acids.

3. As this precipitate could not be fublimed, without being decompounded, like animal matter, $\left(e, 5_{5}\right)$ and alfo, for the reafons mentioned in the laft paragraph, it cannot be the fame thing as the acid fublimate of Scheele, or the fuccinic acid.

4. As it does not appear to be putrefcible, nor form a vifcid folution with water, it cannot be referred to the animal mucilages.

5. On account of its manner of burning in the air, under the blowpipe, $(e, 6$.$) and its yielding, on expofure to fire in$ clofe veffels, the diftinguifhing products of animal matter, (efpecially ammoniac and pruffic acid,) as well as on account of its affording a foap-like matter with cauftic foda, this precipitate may be confidered as a fpecies of animal matter; and, from its compofition being analogous to that of the fubftances called, in the new fyfem of chemifty, animal oxides, it belongs to that genus. Its peculiar and fpecific diftinguifhing properties are, imputrefcilility, fucility of cryjtallization, infolubility in cold water, and, that moft remarkable property of all others, producing a pink or red matter, on evaporation of its folution in nitric acid*.

* It is much to be wished that we possessed equally delicate tests of the other species of animal matter, which are confounded together, although, from their obvious propertics, there is reason to believe they

Vol. II. 
I do not avail myfelf of various other conclufions in this place, becaufe they relate efpecially to the agency of medicines for preventing and removing concretions; and of courfe do not properly fall within the views of the Royal Society.

Having found the above precipitate to be an oside, and not, as is commonly fuppofed, an acid, I thought it probable that, like other analogous oxides, it was acidifiable, and I fufpected that I had really rendered it into the acid ftate, by the nitric acid; which, in the above experiments, $(e, 14$. had imparted oxygen to it, and thereby rendered it foluble, deliquefcent, pungent, and volatile. This change alfo would account for the nitric folution not affording the precipitate.

In order to obtain, for examination, an adequate quantity of this fuppofed acid, the following experiments were inftituted, with the three acids (viz. the oxymuriatic, the nitro-muriatic, and the nitric), which can acidify oxides analogous to the prefent one.

Experiment I. Twenty-five grains of the above animal oxide, (for fo I will now venture to call it,) and three ounces of nitric acid, of the fpecific gravity of $\mathbf{1}, 25$, were put into a retort, and the hydro-pneumatic apparatus was adjoined.

At a very low temperature, a clear folution was made. Firit, foon after the folution began to boil, 23 ounces, by meafure, of colourles gaz came over, which were fucceeded (fecondly), by white fumes, filling the apparatus, and 23 ounces more of gaz. Thirdly, a white fublimate afcended, and there was a frong fmell of pruffic acid. The fublimate was very readily wathed out, being very foluble, and tafted pungent or tharp, but not four. Fourthly, the diftillation being renewed, more white fublimate appeared, but only 3

are of very different kinds, as is the case with the matter of the brain, liver, voluntary muscles, mucus, \&c. Mr. Hunter has discovered a distinguishing specific property of pus, and one is here indicated for the wxide of urinary concretions. 
ounces more of gaz came over; and then the retort only contained a dark-brown folid matter.

The firft portion of gaz, viz. 23 ounces, confifted of about equal bulks of carbonic acid and atmofpherical air. The fecond portion, viz. 23 ounces, was two-thirds of its bulk carbonic acid, and the reft nitrogen gas. The third portion, or 3 ounces, was atmofpherical air, with a little carbonic acid.

Nitric acid was poured, in the fame quantity as before, into the retort. An effervefcence immediately took place, which was fucceeded by a tranfparent folution. The diftillation yielded gaz of the fame kind as before, but in fmaller quantity, with white fumes, and white fublimate. When only about 4 drachms, by meafure, of liquid remained in the retort, a little of it was evaporated ; and, when reduced to a folid matter, it turned black, and took fire, leaving a carbonaceous refidue; but, before this, a margin of beautiful pink matter appeared.

Nitric acid was poured, as before, into the retort, for the third time, but very little gaz afcended, and much lefs white fumes than before. The diftillation proceeded, till about one drachm-meafure of liquid remained in the retort: this being left to ftand, prifmatic cryftals were formed in a very fmall quantity of liquid. Thefe cryftals did not tafte four, but tharp, and they reddened turnfole paper. Adding a little foda to a part of them, to fee whether I could form a neutral falt, I was furprifed by the extrication of ammoniac. To another portion of cryftals I added fulphuric acid, which difengaged nitric acid. A third portion of cryftals, being expofed over a lamp, wholly evaporated, without leaving a mark behind. The remaining matter in the retort being examined, was found to be nitrate of ammoniac. It was plain that the nitric acid had, by parting with oxygen to the carbon of the oxide, formed carbonic acid. The carbon being thus carried off, of courfe the nitrogen and hydrogen of the oxide uniting produce ammoniac; which, uniting with 
the redundant nitric acid, compofes nitrate of ammoniac; but great part of the nitrate of ammoniac was carried off in the vapour ftate, exhibiting white fumes, and fublimate, as above obferved.

The mode of making the experiments with the other acids was of courfe different from the former experiment.

Experiment II. Twenty-five grains of the above animal oxide, and half an ounce of water, were put into a bottle capable of containing three pints; a ftream of oxymuriatic acid gaz, from manganefe and muriatic acid, was made to pars in to the bottle, and upon the charge, for twelve hours; and, for twenty-four hours more, oxymuriatic gaz kept iffuing, but in finaller quantity, and circulating through the bottle. The oxide, by this time, was completely diffolved. Upon adding lime to a little of the folution of it, ammoniac was difengaged; and, upon adding fulphuric acid, there was a difengagement of oxymuriatic acid. On evaporation, however, I obtained nothing but muriate of ammoniac, with which was mixed a little manganefe.

In this experiment, I could not doubt that the carbon had been carried off, in the ftate of carbonic acid, by the oxygen of the oxymuriatic acid; and thus ammoniac was compounded, from the union of the two remaining conftituent parts of the oxide, viz. the nitrogen and hydrogen. The oxymuriatic acid, united to the ammoniac, parted with oxygen, and became muriatic acid during evaporation; hence, muriate of ammoniac was formed.

Experiment III. The above experiment was repeated, only the gaz was nitro-muriatic gaz, from a mixture of nitric and muriatic acids. The refult was the lame as in the laft experiment, except that the product was a mixture of nitrate, and muriate, of ammoniac.

I made other experiments of the fame kind; but their refults were fo nearly the fame as thofe above related, that I thall not give an account of them. By the unexpected iflue of thefe experiments, all my hopes of acidifying the 
animal oxide were exploded; but 1 am indebted to that purfuit for the curious difcovery of the change of the moft common bafis of urinary concretions, (the animal oxide,) into ammoniac and carbonic acid, by the oxygen of the above acids; which will be found extremely important, aa. it enables us to interpret many phænomena, in a variety of cafes befide the prefent. It now appears, that the inflammation mentioned in one of the above experiments, (and which alfo happened in (everal others, ) on evaporation of the nitric folution of the animal oxide, was from the nitrate of ammoniac, the nitrum flammans of the old chemifts, compounded in thofe experiments. This inflammation takes place fometimes, on evaporation of nitric folutions, both of urinary concretions, and of urine itfelf evaporated to the tate of foft extract, on account of the ammoniac already exifting in thefe fubftances. The compofition of ammoniac alfo explains the difappearance of the whole matter of fome forts of urinary concretions, a very fmall refidue of black matter excepted, by repeated affufion and evaporation of nitpic acid, from the folution of them in this menitruum.

It remains for me to give an account of the 96 grains of powdery matter left on the paper ftrainer, $\left(a_{3}\right)$ which are the infoluble portion, in lye of cauftic foda, of 300 grarns of urinary concretions.

r. A fmall portion of the infoluble matter, being expofed to flame with the blowpipe, did not turn black nor yield any fmell of animal matter; but it became whiter; and $I$ could juft agglutinate the powder into one mals, although I was unable to render it fluid.

2. The filtrated liquid, from a little of the matter boiled in water, became very turbid and white with oxalic acjd: with lime water it grew barely curdy; and it did not alter the cobour of turnfole, or of violet juice.

3. The matter diffolved completely in muriatic acid, and alfo in nitric acid, without effervefcence, 
This nitric folution, having been evaporated, to carry off moft of the free acid, inftantly became very curdy on the addition of lime water.

It grew thick and white on adding fulphuric acid, yielding a copious precipitate of fulphate of lime. One portion of the fupernatant liquor upon this precipitate, on evaporation, afforded an extract-like matter; which readily melted, as phofphoric acid does when it is mixed with a little earthy matter. To the other portion of this fupernatant liquor was added liquid cauftic ammoniac, producing a precipitate which afforded no fulphate of magnefia with fulphuric acid.

From thefe experiments it appears, that the above 96 grains of infoluble matter confifted of phofphate of lime. Accordingly, the 300 grains of urinary concretions examined, appear to contain,

Peculiar animal oxide _ _ . $\quad$ grains Phofphate of lime $\quad$ - $\quad$ - $\quad$ - $\quad 96$ Ammoniac, (and moft probably phofphoric acid united to the ammoniac,) water, and common mucilage of urine, which were not collected and weighed, by eftimation

[To be continued.]

IX. Chemical Confiderations on the Ufe of the Oxyds of Iron in dyeing Cotton. By J. A. Chaptal. From the Annales de Chimie, Vol. XXVI.

\section{$\mathrm{T}$}

$\mathrm{HE}$ oxyd of iron has fuch an affinity with cotton thread, that, if the latter be plunged in a faturated folution of iron in any acid whatever, it immediately affumes a chamoy yellow colour, more or lefs dark according to the ftrength of the 